\title{
Are adipokines associated with atrial fibrillation in type 2 diabetes?
}

\author{
Michał Peller ${ }^{1}$, Agnieszka Kapłon-Cieślicka' ${ }^{1}$, Marek Rosiak2 ${ }^{2}$ Agata Tymińska ${ }^{1}$, Krzysztof Ozierański ${ }^{1}$, \\ Ceren Eyileten ${ }^{3}$, Agnieszka Kondracka ${ }^{4}$, Dagmara Mirowska-Guzel' ${ }^{3}$, Grzegorz Opolski ${ }^{1}$, Marek Postuła ${ }^{3}$, \\ Krzysztof J. Filipiak ${ }^{1}$ \\ ${ }^{1} 1^{\text {st }}$ Chair and Department of Cardiology, Medical University of Warsaw, Warsaw, Poland \\ ${ }^{2}$ Department of Cardiology and Hypertension, Central Clinical Hospital, the Ministry of the Interior and Administration, Warsaw, \\ Poland \\ ${ }^{3}$ Centre for Preclinical Research and Technology (CePT), Department of Experimental and Clinical Pharmacology, \\ Medical University of Warsaw, Warsaw, Poland \\ ${ }^{4}$ Department of Internal Diseases and Endocrinology, Medical University of Warsaw, Warsaw, Poland
}

\begin{abstract}
Introduction: The potential effect of adipokines on the development of AF is yet to be established. The aim of this study was to investigate the association of baseline serum adipokines with 1) the presence of AF at baseline and 2) future risk of AF development.

Material and methods: The current study is a sub-analysis of the prospective, randomised AVOCADO (Aspirin Vs./Or Clopidogrel in Aspirin-resistant Diabetics inflammation Outcomes) trial. The AVOCADO study included patients with type 2 DM burdened with at least two additional cardiovascular risk factors and receiving acetylsalicylic acid. In patients included in the current analysis adipokines and inflammatory biomarker levels were measured. Information on the subsequent AF diagnosis was collected after a median of 5.4 years of follow-up.

Results: A total of 273 patients with type $2 \mathrm{DM}$ (median age 68 years; $52 \%$ male) were included in the initial analysis comparing patients with and without AF at baseline. Patients with diagnosed AF (12\%) had higher levels of serum resistin [8.5 (5.8-10.5) vs. 6.9 (5.6-8.7) ng/mL; $\mathrm{p}=0.034$ ], adiponectin [6.9 (5.6-8.7) vs. $2.7(1.8-4.2) \mathrm{ng} / \mathrm{mL} ; \mathrm{p}=0.032]$, and N-terminal pro-B-type natriuretic peptide (336 [148-473] vs. 108 [45-217]; $\mathrm{p}<0.001$ ) than non-AF patients. There were no significant differences in serum leptin, IL-6, and TNF- $\alpha$ concentrations between the two groups. From subjects without known AF at study entry, 19\% developed AF at follow-up. In logistic regression analysis, baseline adipokine levels did not predict $\mathrm{AF}$ development.

Conclusion: In type $2 \mathrm{DM}$, patients with $\mathrm{AF}$ have higher resistin and adiponectin concentrations than patients with no AF. None of the studied adipokines proved a predictor of future AF development. (Endokrynol Pol 2020; 71 (1): 34-41)

Key words: atrial fibrillation; diabetes mellitus; adipokines; resistin; adiponectin; leptin
\end{abstract}

\section{Introduction}

Atrial fibrillation (AF) is one of the most common arrhythmias, with a prevalence of $3 \%$ among adults [1]. Due to its increasing incidence, in the coming decades we are expected to face a pandemic of AF. Diagnosis and treatment of AF are crucial to reduce the risk of thromboembolic events [2,3]. Nowadays, the most challenging task seems to be establishing an AF diagnosis in asymptomatic patients. Therefore, many studies aim to assess risk factors of arrhythmia development and to identify subpopulations with higher risk of AF occurrence. Such subpopulations might benefit from a more rigorous screening for arrhythmia.

Diabetes mellitus (DM) is a well-known risk factor of AF development $[4,5]$. Moreover, previous studies demonstrated that DM elevates the risk of thromboembolic events in patients with diagnosed AF [3]. This risk remains increased even during anticoagulation therapy [6]. Due to similar risk factors contributing to the onset of DM and cardiovascular diseases, AF is diagnosed in up to $15 \%$ of patients with DM [7]. The Framingham study revealed that DM patients have 1.6-times (male) and 1.4-times (female) higher risk of AF, irrespective of other risk factors [5]. The association between DM and AF seems to be bi-directional. This complex relation includes ionic abnormalities, myocardium hypertrophy, and autonomic nervous system disturbances.

Recent studies revealed that adipokines might play an important role in risk assessment in patients with diagnosed DM $[8,9]$. Adipokines are involved in the regulation of insulin sensitivity, endothelial function, inflammatory response, and serum lipid levels [10, 11]. Although the association between DM and AF is well-proven, the potential effect of adipokines on the development of AF is yet to be established. 
The aim of this study was to investigate the association of baseline serum adipokine concentrations with 1) the presence of AF at baseline and 2) future risk of AF development in type $2 \mathrm{DM}$ patients. We focused on four key adipokines: two "classic" adipokines (leptin and resistin) and two inflammatory cytokines released from adipose tissue [interleukin 6 (IL-6) and tumour necrosis factor alpha (TNF- $\alpha)$ ].

\section{Material and methods}

\section{Study group}

The current study is a sub-analysis of the prospective, randomised AVOCADO (Aspirin Vs./Or Clopidogrel in Aspirin-resistant Diabetics inflammation Outcomes) trial. The complete design of the AVOCADO trial, along with its inclusion and exclusion criteria, was described previously [12]. In brief, the AVOCADO study included patients aged between 30 and 80 years, with type $2 \mathrm{DM}$, irrespective of the type of antidiabetic treatment (with the exception of diet-only treated patients), burdened with at least two additional cardiovascular risk factors, and receiving $75 \mathrm{mg}$ of acetylsalicylic acid (ASA) daily. Patients on anticoagulation or other antiplatelet regimens were excluded from the AVOCADO study. The aim of the AVOCADO trial was to assess the effect of an eight-week course of clopidogrel or an increased ASA dose $(150 \mathrm{mg})$ in patients with type $2 \mathrm{DM}$ and high platelet reactivity on lower ASA dose $(75 \mathrm{mg})$ Patients who did not exhibit high platelet reactivity on ASA $75 \mathrm{mg}$ daily continued this treatment. All laboratory assessments included in the present analysis were performed at study entry, i.e. before randomisation to clopidogrel or an increased ASA dose. Data on baseline clinical characteristics (including AF status at enrolment) were obtained during the initial visit in the AVOCADO study by interview, physical examination, electrocardiogram (ECG), and a thorough analysis of all previous medical records (including previous ECGs and Holter-ECGs, if available).

The current study included only those participants of the AVOCADO trial for whom information on baseline AF status as well as measurements of baseline leptin, resistin, IL-6, and TNF- $\alpha$ concentrations were available. These patients were divided into two groups: 1) patients with known paroxysmal, persistent, or permanent $\mathrm{AF}$ at baseline and 2) patients with no known $\mathrm{AF}$ at enrolment. These two groups were compared with respect to clinical and laboratory characteristics (including adipokine levels).

After a median of 5.4 years, patients with no known AF at study entry were contacted by telephone, and information on the diagnosis of AF at follow-up was collected. During the telephone call, a thorough analysis of the patient's medical documentation and current pharmacotherapy was carried out in order to establish a credible diagnosis of AF. Data on survival were obtained from the National ID Number Database. Patients who died during follow-up were excluded from the final analysis.

The AVOCADO study protocol was accepted by the Local Ethical Review Board, and every patient signed an informed consent form to participate in the study.

\section{Laboratory assessments}

All laboratory parameters were measured in blood samples collected from all subjects in the morning after overnight fasting during an outpatient visit. Haematology and biochemical parameters were measured, including complete blood count, ions, creatinine, lipid profile, glucose, glycated haemoglobin, and high-sensitivity C-reactive protein (CRP).

Additionally, in all patients included in the current analysis, leptin, resistin, IL-6, and TNF- $\alpha$ levels were assessed. All serum samples were stored at a temperature of $-80^{\circ} \mathrm{C}$ before the laboratory assessment. The following kits were used for evaluation of adipokine levels: Human Leptin Quantikine ELISA Kit ${ }^{\circledR}$ (R\&D Systems Inc., Minneapolis, Minnesota, United States), Human Resistin Quantikine ELISA Kit ${ }^{\circledR}$ (R\&D Systems Inc.), Quantikine HS ELISA Human TNF- $\alpha$ Immunoassay ${ }^{\circledR}$ (R\&D Systems Inc.), and Quantikine HS ELISA Human IL-6 Immunoassay ${ }^{\circledR}$ (R\&D Systems Inc.). The baseline high-molecular weight (HMW) adiponectin concentration was assessed for 190 patients using Human HMW Adiponectin Quantikine ELISA Kit ${ }^{\circledR}$ (R\&D Systems Inc.).

\section{Study endpoint}

The study endpoint was AF diagnosed during the follow-up period. Only an AF diagnosis confirmed by the patient's medical documentation was considered as an endpoint.

\section{Statistical analysis}

All categorical and continuous variables were presented as percentages and median values with interquartile ranges (IQR), respectively. Continuous variables were non-normally distributed, which was calculated with the Shapiro-Wilk test. Differences between subgroups were assessed with Fisher's exact test and the Mann-Whitney U test, respectively, for categorical and continuous variables. Univariate logistic regression was used to identify predictors of AF onset. A multivariate logistic regression model was developed including risk factors with $\mathrm{p}<0.1$ in univariate logistic regression. Tests were considered significant for $\mathrm{p}$-values $<0.05$. Statistical analysis was calculated using $\mathrm{SAS} \circledast$ software, version 9.4 .

\section{Results}

A total of 273 patients with type $2 \mathrm{DM}$ (median age: 68 years, IQR: $61-74$ years, $52 \%$ male) were included in the initial analysis comparing patients with and without $\mathrm{AF}$ at baseline. Complete follow-up for subjects without known AF at study entry, with a median duration of 5.4 years (IQR 4.8-5.9 years), was obtained for 171 patients. A flowchart of patient selection in the present analysis is shown in Figure 1.

\section{Comparison of patients with and without AF at baseline}

At study entry, 30 patients (11\%) had known AF. Comparison between patients with and without AF at study entry revealed higher levels of serum resistin, adiponectin, and N-terminal pro-B-type natriuretic peptide (NT-proBNP) in patients with diagnosed AF. A trend towards higher serum level of IL- 6 was noted in patients with AF. There was no difference in serum leptin and TNF- $\alpha$ concentrations between the two groups. We observed higher prevalence of heart failure and a trend towards older age in patients with diagnosed AF compared to patients without AF. Baseline characteristics of analysed groups are presented in Table 1.

\section{Predictors of AF development at follow-up}

Out of 171 patients with no AF at baseline and a complete follow-up, AF was diagnosed in $33(19 \%)$ patients. In univariate analysis, baseline adipokine levels did not predict AF development. We observed higher 


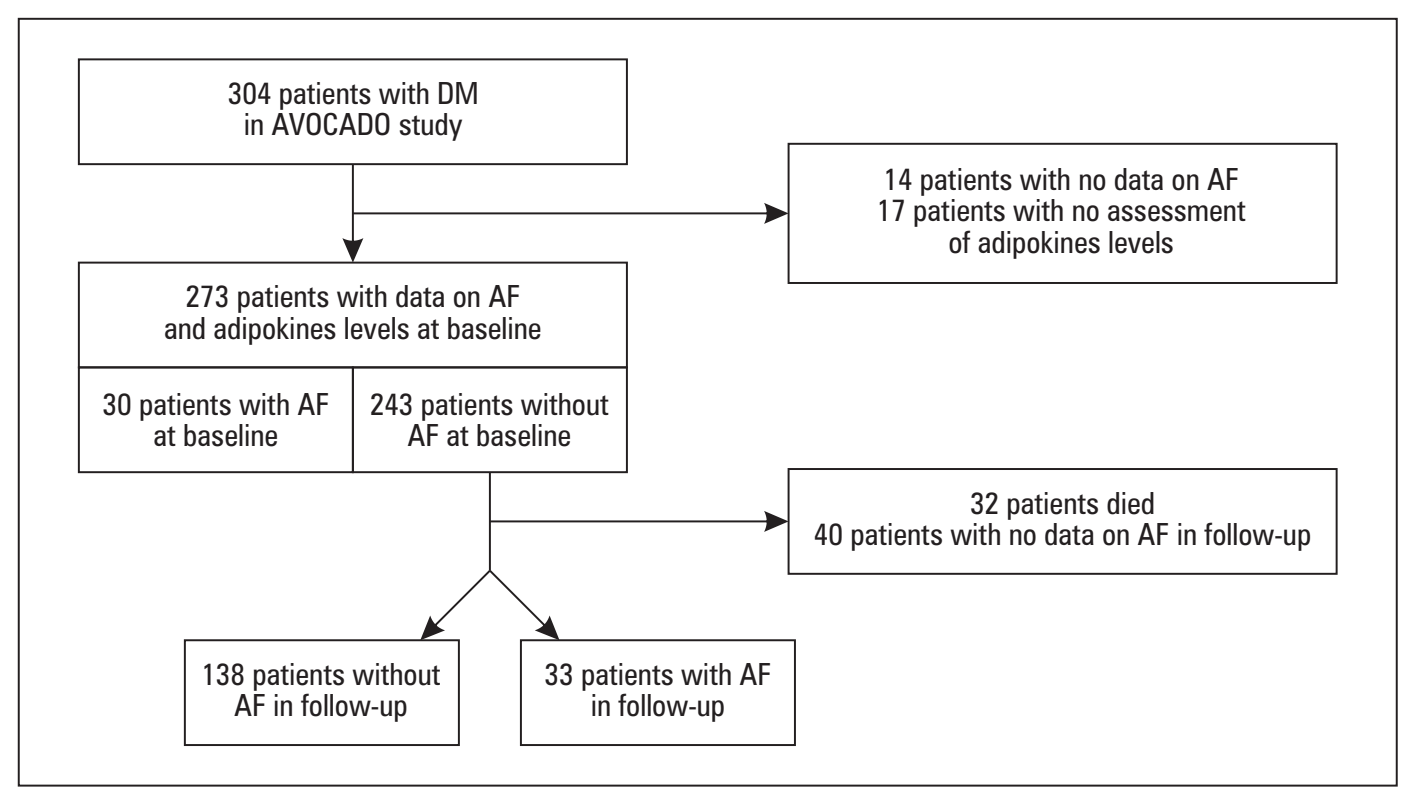

Figure 1. Flowchart of subgroups selection. AF — atrial fibrillation; DM - diabetes mellitus; pts — patients

Table 1. Baseline characteristics of patients with and without atrial fibrillation (AF) at study entry

\begin{tabular}{|c|c|c|c|c|}
\hline & $\begin{array}{c}\text { Total } \\
\text { (n= 273) }\end{array}$ & $\begin{array}{l}\text { No } A F \text { at baseline } \\
(n=243)\end{array}$ & $\begin{array}{c}\text { AF at baseline } \\
(\mathrm{n}=\mathbf{3 0})\end{array}$ & p value \\
\hline \multicolumn{5}{|l|}{ Demographics } \\
\hline Age [years] & $68(61-74)$ & $68(60-74)$ & $71(64-76)$ & 0.08 \\
\hline Male & $52 \%$ & $52 \%$ & $53 \%$ & 1.00 \\
\hline \multicolumn{5}{|l|}{ Clinical assessment } \\
\hline Body mass index $\left[\mathrm{kg} / \mathrm{m}^{2}\right]$ & $30.3(27.1-33.1)$ & $30.3(27.1-33.1)$ & $30.2(26.8-33.0)$ & 0.73 \\
\hline Waist-hip ratio & $0.97(0.91-1.03)$ & $0.97(0.91-1.03)$ & $0.96(0.90-1.01)$ & 0.38 \\
\hline Systolic blood pressure [mm Hg] & $140(130-150)$ & $140(130-150)$ & $138(120-155)$ & 0.29 \\
\hline Diastolic blood pressure [mm Hg] & $80(70-86)$ & $80(70-86)$ & $80(70-86)$ & 0.43 \\
\hline Heart rate [beats/min] & $70(65-78)$ & $72(65-79)$ & $70(64-71)$ & 0.053 \\
\hline \multicolumn{5}{|l|}{ Medical history } \\
\hline Diabetes mellitus duration [years] & $8(3-15)$ & $8(3-15)$ & $6(2-14)$ & 0.24 \\
\hline Diabetes mellitus treated with oral antidiabetic drugs & $86 \%$ & $86 \%$ & $90.0 \%$ & 0.80 \\
\hline Metformin & $61 \%$ & $62 \%$ & $50.5 \%$ & 0.24 \\
\hline Diabetes mellitus treated with insulin & $29 \%$ & $30 \%$ & $20.0 \%$ & 0.29 \\
\hline Hypertension & $93 \%$ & $93 \%$ & $93 \%$ & 1.00 \\
\hline Ischaemic heart disease & $55 \%$ & $55 \%$ & $53 \%$ & 0.85 \\
\hline Dyslipidaemia & $82 \%$ & $83 \%$ & $73 \%$ & 0.21 \\
\hline Prior myocardial infarction & $30 \%$ & $30 \%$ & $37 \%$ & 0.53 \\
\hline Chronic heart failure & $37 \%$ & $35 \%$ & $55 \%$ & 0.042 \\
\hline Prior ischaemic stroke & $7.0 \%$ & $6.6 \%$ & $10 \%$ & 0.45 \\
\hline History of smoking & $57 \%$ & $58 \%$ & $53 \%$ & 0.70 \\
\hline \multicolumn{5}{|l|}{ Laboratory findings } \\
\hline White blood cells [1000/mcL] & $6.7(5.7-7.8)$ & $6.7(5.8-7.7)$ & $6.8(5.4-9.3)$ & 0.66 \\
\hline Haemoglobin [g/dL] & $13.9(13.0-14.7)$ & $13.9(13.0-14.8)$ & $14.0(13.1-14.4)$ & 0.87 \\
\hline Estimated glomerular filtration rate $\left[\mathrm{mL} / \mathrm{min} / 1.73 \mathrm{~m}^{2}\right]$ & $69.2(56.6-83.7)$ & $69.5(56.7-84.9)$ & $65.6(54.8-77.3)$ & 0.37 \\
\hline
\end{tabular}


Table 1. Baseline characteristics of patients with and without atrial fibrillation (AF) at study entry

\begin{tabular}{|c|c|c|c|c|}
\hline & $\begin{array}{c}\text { Total } \\
(\mathrm{n}=273)\end{array}$ & $\begin{array}{l}\text { No } \mathrm{AF} \text { at baseline } \\
\quad(\mathrm{n}=243)\end{array}$ & $\begin{array}{c}\text { AF at baseline } \\
(\mathrm{n}=30)\end{array}$ & $\mathrm{p}$ value \\
\hline Sodium $[\mathrm{mmol} / \mathrm{L}]$ & $141.2(139.1-142.9)$ & $141.1(138.8-142.9)$ & $142.1(140.3-142.9)$ & 0.07 \\
\hline Potassium [mmol/L] & $4.5(4.2-4.7)$ & $4.4(4.2-4.7)$ & $4.5(4.2-4.6)$ & 0.95 \\
\hline Total cholesterol [mg/dL] & $160(139-186)$ & $161(140-186)$ & $158(134-198)$ & 0.75 \\
\hline Low-density lipoprotein [mg/dL] & $85(65-107)$ & $85(66-106)$ & $79(63-116)$ & 0.94 \\
\hline High-density lipoprotein [mg/dL] & $47(39-56)$ & $47(39-56)$ & $46(40-57)$ & 1.00 \\
\hline Triglycerides [mg/dL] & $123(91-164)$ & $124(92-165)$ & $114(89-153)$ & 0.48 \\
\hline Glycated haemoglobin (\%) & $6.6(6.1-7.6)$ & $6.7(6.2-7.7)$ & $6.4(5.7-7.1)$ & 0.018 \\
\hline Leptin [ng/mL] & $18.0(9.4-32.4)$ & $18.0(9.4-32.4)$ & $18.8(7.8-36.0)$ & 0.93 \\
\hline Resistin [ng/mL] & $7.0(5.6-9.0)$ & $6.9(5.6-8.7)$ & $8.5(5.8-10.5)$ & 0.034 \\
\hline Adiponectin [ng/mL] & $\begin{array}{c}2.9(1.9-4.4) \\
{[n=190]}\end{array}$ & $\begin{array}{c}2.7(1.8-4.2) \\
{[\mathrm{n}=167]}\end{array}$ & $\begin{array}{c}3.6(2.7-6.0) \\
{[n=23]}\end{array}$ & 0.032 \\
\hline Tumour necrosis factor alpha $[\mathrm{pg} / \mathrm{mL}]$ & $1.8(1.2-2.3)$ & $1.8(1.2-2.3)$ & $2.0(1.3-2.5)$ & 0.39 \\
\hline Interleukin 6 [pg/mL] & $2.4(1.5-4.2)$ & $2.3(1.5-4.0)$ & $3.3(1.6-5.4)$ & 0.09 \\
\hline High sensitivity C-reactive protein [mg/L] & $2.6(1.4-4.5)$ & $2.6(1.5-4.5)$ & $3.1(1.3-5.0)$ & 0.74 \\
\hline $\mathrm{N}$-terminal pro-B-type natriuretic peptide $[\mathrm{pg} / \mathrm{mL}]$ & $117(53-252)$ & $108(45-217)$ & $336(148-473)$ & $<0.001$ \\
\hline \multicolumn{5}{|l|}{ Concomitant medications } \\
\hline Beta-blockers & $73 \%$ & $71 \%$ & $86 \%$ & 0.12 \\
\hline Angiotensin-converting enzyme inhibitors & $66 \%$ & $67 \%$ & $52 \%$ & 0.10 \\
\hline Calcium channel blockers & $39 \%$ & $41 \%$ & $24 \%$ & 0.10 \\
\hline Nitrates & $5.9 \%$ & $5.0 \%$ & $14 \%$ & 0.08 \\
\hline Loop diuretics & $17 \%$ & $16 \%$ & $32 \%$ & 0.038 \\
\hline Thiazide diuretics & $7.4 \%$ & $7.0 \%$ & $10 \%$ & 0.46 \\
\hline Indapamide & $29 \%$ & $30 \%$ & $17 \%$ & 0.19 \\
\hline Mineralocorticoid receptor antagonists & $5.9 \%$ & $5.8 \%$ & $6.9 \%$ & 0.68 \\
\hline Angiotensin receptor blockers & $20 \%$ & $19 \%$ & $28 \%$ & 0.32 \\
\hline Statins & $73 \%$ & $74 \%$ & $73 \%$ & 1.00 \\
\hline Fenofibrate & $13 \%$ & $13 \%$ & $14 \%$ & 1.00 \\
\hline Digoxin & $1.5 \%$ & $0.8 \%$ & $6.9 \%$ & 0.06 \\
\hline
\end{tabular}

risk of AF onset in patients with a history of myocardial infarction. There were trends towards a higher risk of AF onset in patients with higher NT-proBNP concentration, a history of ischaemic heart disease, and longer DM history (Tab. 2). In multivariate logistic regression analysis, only a history of myocardial infarction proved an independent risk factor of AF development (Tab. 3).

\section{Discussion}

In the studied group of type $2 \mathrm{DM}$ patients, serum concentrations of adipokines were not associated with future AF development. However, patients with a diagnosis of AF at baseline had higher serum levels of resistin and adiponectin, and a trend towards higher IL-6 concentration compared with patients without known AF.

\section{Baseline adipokine levels and future atrial fibrillation development}

In contrast to our study, Ermakov at al. revealed that in a group of postmenopausal women (50-79 years-old), during over 11 years of observation, serum resistin levels were independently associated with new AF onset [13]. The authors concluded that resistin may be considered as a biomarker that partially mediates the relationship between obesity and AF. Notably, the incidence of new AF onset in the group of postmenopausal women was similar to that seen in our study ( $18.1 \%$ vs. $19.3 \%$, respectively), but the duration of follow-up was twice as long. This shows that DM and other cardiovascular diseases requiring antiplatelet treatment (present in our study group) should be considered strong risk factors of AF development. So far, there are no data on resistin or 
Table 2. Univariate logistic regression analysis of predictors of atrial fibrillation development at follow-up

\begin{tabular}{|c|c|c|}
\hline & OR (95\% Cl) & $\mathrm{p}$ value \\
\hline \multicolumn{3}{|l|}{ Demographics } \\
\hline Age [per 10 years] & $1.07(0.69-1.67)$ & 0.759 \\
\hline Male & $0.89(0.42-1.90)$ & 0.760 \\
\hline \multicolumn{3}{|l|}{ Clinical assessment } \\
\hline Body mass index [per kg/m²] & $1.02(0.94-1.11)$ & 0.618 \\
\hline Waist-hip ratio [per 0.1] & $1.31(0.87-1.97)$ & 0.198 \\
\hline Systolic blood pressure [per $10 \mathrm{~mm} \mathrm{Hg}$ ] & $0.91(0.74-1.11)$ & 0.346 \\
\hline Diastolic blood pressure [per $10 \mathrm{~mm} \mathrm{Hg}$ ] & $0.79(0.57-1.10)$ & 0.162 \\
\hline Heart rate [per 10 beats/min] & $0.77(0.52-1.15)$ & 0.203 \\
\hline \multicolumn{3}{|l|}{ Medical history } \\
\hline Diabetes mellitus duration [per 10 years] & $1.44(0.98-2.12)$ & 0.065 \\
\hline Diabetes mellitus treated with oral antidiabetic drugs & $0.47(0.16-1.34)$ & 0.158 \\
\hline Diabetes mellitus treated with insulin & $1.14(0.50-2.63)$ & 0.751 \\
\hline Hypertension & $0.79(0.21-3.06)$ & 0.737 \\
\hline Ischaemic heart disease & $2.00(0.90-4.44)$ & 0.089 \\
\hline Dyslipidaemia & $0.50(0.20-1.23)$ & 0.144 \\
\hline Prior myocardial infarction & $3.52(1.60-7.75)$ & 0.002 \\
\hline Chronic heart failure & $1.56(0.72-3.43)$ & 0.253 \\
\hline Prior ischaemic stroke & $1.28(0.33-4.94)$ & 0.720 \\
\hline History of smoking & $1.12(0.51-2.42)$ & 0.783 \\
\hline \multicolumn{3}{|l|}{ Laboratory findings } \\
\hline White blood cells [per 1000/mcL] & $1.11(0.92-1.35)$ & 0.281 \\
\hline Haemoglobin [per g/dL] & $0.81(0.61-1.09)$ & 0.162 \\
\hline Estimated glomerular filtration rate [per $10 \mathrm{~mL} / \mathrm{min} / 1.73 \mathrm{~m}^{2}$ ] & $1.03(0.86-1.22)$ & 0.786 \\
\hline Sodium [per mmol/L] & $0.89(0.78-1.03)$ & 0.108 \\
\hline Potassium [per mmol/L] & $0.60(0.24-1.48)$ & 0.268 \\
\hline Total cholesterol [per 10 mg/dL] & $0.96(0.86-1.07)$ & 0.477 \\
\hline Low-density lipoprotein [per 10 mg/dL] & $0.97(0.85-1.11)$ & 0.668 \\
\hline High-density lipoprotein [per 10 mg/dL] & $0.89(0.66-1.20)$ & 0.441 \\
\hline Triglycerides [per $10 \mathrm{mg} / \mathrm{dL}$ ] & $1.03(0.97-1.08)$ & 0.322 \\
\hline Glycated haemoglobin [per \%] & $1.20(0.91-1.59)$ & 0.201 \\
\hline Leptin [per $\mathrm{ng} / \mathrm{mL}]$ & $0.99(0.97-1.02)$ & 0.535 \\
\hline Resistin [per ng/mL] & $1.07(0.96-1.20)$ & 0.199 \\
\hline Adiponectin [ng/mL] & $0.94(0.74-1.12)$ & 0.597 \\
\hline Tumour necrosis factor alpha [per $0.1 \mathrm{pg} / \mathrm{mL}$ ] & $1.02(0.99-1.05)$ & 0.160 \\
\hline Interleukin 6 [per $0.1 \mathrm{pg} / \mathrm{mL}$ ] & $1.01(0.99-1.02)$ & 0.224 \\
\hline High sensitivity C-reactive protein [per mg/L] & $1.03(0.98-1.09)$ & 0.228 \\
\hline N-terminal pro-B-type natriuretic peptide [per $100 \mathrm{pg} / \mathrm{mL}$ ] & $1.10(0.99-1.22)$ & 0.077 \\
\hline
\end{tabular}

$\mathrm{OR}$ - odds ratio; $\mathrm{Cl}$ - confidence interval

its receptors as potential targets for intervention to reduce the incidence of $\mathrm{AF}$.

Similar results were presented in a sub-analysis of the Framingham study [14]. During a follow-up of $7.6 \pm 2.0$ years new AF development was observed in $8.3 \%$ of patients. However, the effect of resistin lost sig- nificance after adjustment for CRP. The authors did not observe any relationship between serum adiponectin level and the risk of AF development.

The potential role of resistin in the pathophysiology of AF is not clear. Resistin is associated with other risk factors of $\mathrm{AF}$, such as $\mathrm{DM}$ and coronary artery 
Table 3. Multivariate logistic regression analysis of predictors of atrial fibrillation development at follow-up

\begin{tabular}{lcc}
\hline & OR (95\% Cl) & p value \\
\hline Diabetes mellitus duration [per year] & $1.02(0.98-1.06)$ & 0.342 \\
\hline Ischaemic heart disease & $1.06(0.38-2.94)$ & 0.911 \\
\hline Prior myocardial infarction & $3.11(1.16-8.34)$ & 0.025 \\
\hline N-terminal pro-B-type natriuretic peptide $[\mathrm{per} 100 \mathrm{pg} / \mathrm{mL}]$ & $1.08(0.92-1.33)$ & 0.158 \\
\hline
\end{tabular}

$\mathrm{Cl}$ - confidence interval

disease, but in the presented studies the effect of resistin on AF onset was observed even after adjustment for traditional risk factors of AF development. High serum resistin level may reflect increased systemic inflammatory response. Previous studies revealed strong correlation between resistin and CRP, IL-6, and TNF- $\alpha$ levels. Secretion of all these substances is regulated by nuclear factor- $\kappa \mathrm{B}$ pathway [15]. Resistin is also related to reduced contractility and hypertrophy of cardiomyocytes [16]. Moreover, resistin is an independent risk factor of unfavourable outcome in patients with type 2 DM [17].

The effect of adiponectin and leptin on AF development has not yet been established. The study of Ermakov et. al, cited above, revealed no relationship between serum leptin level and AF development. A different study showed a strong relationship between serum leptin concentration and risk of heart failure and other cardiovascular diseases [18]. However, this effect was attenuated after adjustment for body mass index. In an animal model, leptin was involved in cardiac fibrosis [19]. This effect was not fully proven in humans. The lack of relationship between serum adiponectin level and new AF onset in our study contrasts with that of Ermakov et al. [13]. In the whole cohort, no effect of adiponectin level on AF development was noted. However, in a subgroup of patients with treated DM, adiponectin was a strong predictor of subsequent AF diagnosis. Patients in the fourth quartile of serum adiponectin levels had an over six-fold higher risk of AF development compared with patients in the first quartile. Similarly, Macheret et al. revealed that in a group of 2376 elderly patients (mean age: $74 \pm 5$ years) with no chronic cardiovascular disease, higher serum adiponectin level was related to an increased risk of new AF [20]. The presented relationship contrasts with the well-described protective role of adiponectin, which is considered an anti-inflammatory and insulin-sensitising hormone [21]. This adiponectin "paradox" might be explained by possible adiponectin resistance and related to higher serum adiponectin level in older patients and in patients with diagnosed cardiovascular diseases [22, 23].

\section{Other risk factors of atrial fibrillation development}

The association of prior myocardial infarction with subsequent AF development, observed in our study, was also shown in other studies. In the analysis of 4764 Framingham Heart Study participants, after adjustment for age and gender, myocardial infarction was associated with an almost 1.5 -fold higher risk of new AF onset [24]. This relationship seems to be complex and may be partially explained by a more intense inflammatory response and a higher risk of heart failure in patients with a history of myocardial infarction [25].

\section{Adipokine levels in patients with a current diagnosis of atrial fibrillation}

Despite no effect of analysed adipokines on future AF development, our study showed higher serum levels of resistin and adiponectin in patients with diagnosed AF compared with non-AF patients. In a study by Özcan et al., when compared with a control group matched for demographics and clinical characteristics, patients with AF had higher serum resistin levels [26]. In the AF group, higher serum levels of CRP were also observed. These results suggest a relationship between resistin and systemic inflammatory response. Another study showed higher serum adiponectin levels in patients with persistent AF compared with patients with paroxysmal AF and a control group [27]. This relationship might be explained by hyposensitivity of adiponectin receptors in AF patients and higher secretion of adiponectin in this group. In a study by Kim et al., higher serum adiponectin level was associated with recurrences of AF after pulmonary vein isolation [28]. This observation implies unfavourable atrial remodelling in patients with higher adiponectin levels. In our study, we observed a trend towards higher serum levels of IL-6 in patients with AF compared to patients without AF. This finding confirms the role of inflammation in the pathogenesis of AF. Similarly, Marcus et al. analysed a group of patients with coronary artery disease and showed elevated levels of IL-6 in patients with AF compared to patients without AF [29]. Interestingly, no association between CRP and AF was found. This observation proved that inflammation affects AF 
development via a CRP-independent pathway. In our analysis, we did not observe differences in the levels of CRP or TNF- $\alpha$ between patients with and without AF. However, a previous study showed that higher TNF- $\alpha$ may be related to larger left atrium and involved in AF development [30]. In an animal model, TNF- $\alpha$ was associated with atrial fibrosis mainly through the influence on TNF- $\beta$ signalling pathway [31].

\section{Study group considerations}

One of the exclusion criteria in the AVOCADO study was anticoagulation therapy. This decreased the number of patients with AF at baseline in the studied population. Nonetheless, at the time of patient recruitment to the AVOCADO study, ASA was approved for stroke prevention in moderate-risk patients (i.e. with 1 point in the $\mathrm{CHADS}_{2}$ score) or in patients with contraindications to oral anticoagulation [32]. In an observational study, including over $17,000 \mathrm{DM}$ patients aged between 65 and 74 years old, Nichols et al. reported AF with a prevalence of $7 \%$ [33]. Baseline AF prevalence in our study was $11 \%$. Importantly, despite differences in resistin and adiponectin concentrations, we observed comparable values of body mass index and waist-hip ratio in patients with and without AF at baseline.

\section{Study limitations}

An important limitation of our analysis is that the AVOCADO study was primarily designed to assess laboratory response to antiplatelet treatment, which affected baseline characteristics of the study population. Secondly, the analysed group was quite heterogenous, with an interquartile range of DM duration ranging from 3 to 15 years, and with a wide spectrum of antidiabetic and cardiovascular pharmacological regimens. Furthermore, a larger study group and a longer follow-up might have revealed possible associations between adipokine levels and the risk of subsequent AF development. Almost $17 \%$ of patients were lost to follow-up. Finally, our analysis was based on a currently known diagnosis of AF (and in follow-up, this information was obtained from the patients via telephone). No additional tests, such as Holter ECG monitoring, were used to detect asymptomatic AF episodes. This might have resulted in a false classification of some patients with silent $\mathrm{AF}$ as non-AF patients.

\section{Conclusion}

In type $2 \mathrm{DM}$, patients with $\mathrm{AF}$ have higher resistin and adiponectin concentrations than patients with no AF. Among patients with no AF at baseline who survived to follow-up, one in five developed AF at five years. In this group, none of the studied adipokines proved to be a predictor of future AF development.

\section{Key messages}

Patients with a diagnosis of atrial fibrillation (AF) at baseline had higher serum levels of resistin and adiponectin compared with patients without known AF.

In the studied group of type 2 diabetes mellitus patients, serum concentrations of adipokines were not associated with future AF development

\section{Acknowledgements}

The AVOCADO study was supported financially partly by the European Union - the European Regional Development Fund within the Operational Program "Innovative economy" for 2007-2013 — and by the research grant from the Polish Pharmaceutical Company ADAMED for a Young Scientist 2007 Award.

\section{Author contributions}

M.Pe. and A.K.-C. designed the present study and conducted data analysis and interpretation. M.Pe. and A.K.-C. wrote the manuscript. A.K. C., A.T., M.Po., M.R., K.O., C.E. conducted data research. M.Pe. performed statistical analysis. A.K. performed laboratory tests. D. M.-G., M.Po., K.J.F., and G.O. designed the AVOCADO study. All authors reviewed the manuscript and approved its final version.

\section{Author disclosures}

Conflicts of interest: none.

\section{References}

1. Kirchhof P, Benussi S, Kotecha D, et al. 2016 ESC Guidelines for the management of atrial fibrillation developed in collaboration with EACTS. Eur Heart J. 2016; 37(38): 2893-2962, doi: 10.1093/eurheartj/ehw210, indexed in Pubmed: 27567408.

2. Kishore A, Vail A,Majid A, et al. Detection of atrial fibrillation after ischemic stroke or transient ischemic attack: a systematic review and meta-analysis. Stroke. 2014; 45(2): 520-526, doi: 10.1161/STROKEAHA.113.003433, indexed in Pubmed: 24385275.

3. Henriksson KM, Farahmand B, Åsberg S, et al. Comparison of cardiovascular risk factors and survival in patients with ischemic or hemorrhagic stroke. Int J Stroke. 2012; 7(4): 276-281, doi: 10.1111/j.1747-4949.2011.007 06.x, indexed in Pubmed: 22151650.

4. Aksnes TA, Schmieder RE, Kjeldsen SE, et al. Impact of new-onset diabetes mellitus on development of atrial fibrillation and heart failure in high-risk hypertension (from the VALUE Trial). Am J Cardiol. 2008; 101(5): 634-638, doi: 10.1016/j.amjcard.2007.10.025, indexed in Pubmed: 18308012

5. Benjamin EJ, Levy D, Vaziri SM, et al. Independent risk factors for atrial fibrillation in a population-based cohort. The Framingham Heart Study. JAMA. 1994; 271(11): 840-844, indexed in Pubmed: 8114238.

6. Ashburner JM, Go AS, Chang Y, et al. Effect of Diabetes and Glycemic Control on Ischemic Stroke Risk in AF Patients: ATRIA Study. J Am Coll Cardiol. 2016; 67(3): 239-247, doi: 10.1016/j.jacc.2015.10.080, indexed in Pubmed: 26796386.

7. Sun $\mathrm{Y}, \mathrm{Hu} \mathrm{D}$. The link between diabetes and atrial fibrillation: cause or correlation? J Cardiovasc Dis Res. 2010; 1(1): 10-11, doi: 10.4103/0975-3583.59978, indexed in Pubmed: 21188083

8. Mattu HS, Randeva HS. Role of adipokines in cardiovascular disease. J Endocrinol. 2013; 216(1): T17-T36, doi: 10.1530/JOE-12-0232, indexed in Pubmed: 23160967. 
9. Wojciechowska C, Jacheć W, Romuk E, et al. The effect of BMI, serum leptin, and adiponectin levels on prognosis in patients with non-ischaemic dilated cardiomyopathy. Endokrynol Pol. 2017; 68(1): 26-34, doi: 10.5603/EP.2017.0005, indexed in Pubmed: 28255978.

10. Horakova D, Stepanek L, Nagelova R, et al. Total and high-molec ular-weight adiponectin levels and prediction of insulin resistance. Endokrynol Pol. 2018; 69(4): 375-380, doi: 10.5603/EP.a2018.0035, indexed in Pubmed: 29952412.

11. Kapłon-Cieślicka A, Postuła M, Rosiak M, et al. Association of adipokines and inflammatory markers with lipid control in type 2 diabetes. Pol Arch Med Wewn. 2015; 125(6): 414-423, doi: 10.20452/pamw.2880, indexed in Pubmed: 25978118.

12. Postula M, Kaplon-Cieslicka A, Rosiak M, et al. Genetic determinants of platelet reactivity during acetylsalicylic acid therapy in diabetic patients: evaluation of 27 polymorphisms within candidate genes. J Thromb Haemost. 2011; 9(11): 2291-2301, doi: 10.1111/j.1538-7836.2011.04482.x, indexed in Pubmed: 21854539.

13. Ermakov S, Azarbal F, Stefanick ML, et al. The associations of leptin, adiponectin and resistin with incident atrial fibrillation in women. Heart. 2016; 102(17): 1354-1362, doi: 10.1136/heartjnl-2015-308927, indexed in Pubmed: 27146694.

14. Rienstra M, Sun JX, Lubitz SA, et al. Plasma resistin, adiponectin, and risk of incident atrial fibrillation: the Framingham Offspring Study. Am Heart J. 2012; 163(1): 119-124.e1, doi: 10.1016/j.ahj.2011.09.029, indexed in Pubmed: 22172445.

15. Gharibeh MY, Al Tawallbeh GM, Abboud MM, et al. Correlation of plasma resistin with obesity and insulin resistance in type 2 diabetic patients. Diabetes Metab. 2010; 36(6 Pt 1): 443-449, doi: 10.1016/j.diabet.2010.05.003, indexed in Pubmed: 20739208.

16. Kim M, Oh JK, Sakata S, et al. Role of resistin in cardiac contractility and hypertrophy. J Mol Cell Cardiol. 2008; 45(2): 270-280, doi: 10.1016/j. yjmcc.2008.05.006, indexed in Pubmed: 18597775.

17. Kapłon-Cieślicka A, Tymińska A, Rosiak M, et al. Resistin is a prognostic factor for death in type 2 diabetes. Diabetes Metab Res Rev. 2019; 35(2): e3098, doi: 10.1002/dmrr.3098, indexed in Pubmed: 30447052.

18. Lieb W, Sullivan LM, Harris TB, et al. Plasma leptin levels and incidence of heart failure, cardiovascular disease, and total mortality in elderly individuals. Diabetes Care. 2009; 32(4): 612-616, doi: 10.2337/dc08-1596, indexed in Pubmed: 19114611.

19. Martínez-Martínez E, Jurado-López R, Valero-Muñoz M, et al. Leptin induces cardiac fibrosis through galectin-3, mTOR and oxidative stress: potential role in obesity. J Hypertens. 2014; 32(5): 1104-1114, doi: 10.1097/HJH.0000000000000149, indexed in Pubmed: 24695395.

20. Macheret F, Bartz TM, Djousse L, et al. Higher circulating adiponectin levels are associated with increased risk of atrial fibrillation in older adults. Heart. 2015; 101(17): 1368-1374, doi: 10.1136/heartjnl-2014-307015, indexed in Pubmed: 25855796.

21. Karmazyn M, Purdham DM, Rajapurohitam V, et al. Signalling mechanisms underlying the metabolic and other effects of adipokines on the heart. Cardiovasc Res. 2008; 79(2): 279-286, doi: 10.1093/cvr/cvn115, indexed in Pubmed: 18474523.
22. Kizer JR. Adiponectin, cardiovascular disease, and mortality: parsing the dual prognostic implications of a complex adipokine. Metabolism. 2014; 63(9): 1079-1083, doi: 10.1016/j.metabol.2014.06.011, indexed in Pubmed: 25038728

23. Menzaghi C, Trischitta V. The Adiponectin Paradox for All-Cause and Cardiovascular Mortality. Diabetes. 2018; 67(1): 12-22 doi: 10.2337/dbi17-0016, indexed in Pubmed: 2926316.

24. Schnabel RB, Sullivan LM, Levy D, et al. Development of a risk score for atrial fibrillation (Framingham Heart Study): a community-based cohort study. Lancet. 2009; 373(9665): 739-745, doi: 10.1016/S0140-6736(09)60443-8, indexed in Pubmed: 19249635.

25. Parashar S, Kella D, Reid KJ, et al. New-onset atrial fibrillation after acute myocardial infarction and its relation to admission biomarkers (from the TRIUMPH registry). Am J Cardiol. 2013; 112(9): 1390-1395, doi: 10.1016/j. amjcard.2013.07.006, indexed in Pubmed: 24135301.

26. Özcan KS, Güngör B, Altay S, et al. Increased level of resistin predicts development of atrial fibrillation. J Cardiol. 2014; 63(4): 308-312, doi: 10.1016/j.jjcc.2013.10.008, indexed in Pubmed: 24268420.

27. Shimano M, Shibata R, Tsuji $Y$, et al. Circulating adiponectin levels in patients with atrial fibrillation. Circ J. 2008; 72(7): 1120-1124 doi: 10.1253/circj.72.1120, indexed in Pubmed: 18577821.

28. Kim TH, Lee JS, Uhm JS, et al. High circulating adiponectin level is associated with poor clinical outcome after catheter ablation for paroxysmal atrial fibrillation. Europace. 2018; 20(8): 1287-1293, doi: 10.1093/europace/eux173, indexed in Pubmed: 29016783.

29. Marcus GM, Whooley MA, Glidden DV, et al. Interleukin-6 and atrial fibrillation in patients with coronary artery disease: data from the Heart and Soul Study. Am Heart J. 2008; 155(2): 303-309, doi: 10.1016/j. ahj.2007.09.006, indexed in Pubmed: 18215601.

30. Deng H, Xue Ym, Zhan Xz, et al. Role of tumor necrosis factor-alpha in the pathogenesis of atrial fibrillation. Chin Med J (Engl). 2011; 124(13): 1976-1982, indexed in Pubmed: 22088456.

31. Liew R, Khairunnisa K, Gu Y, et al. Role of tumor necrosis factor- in the pathogenesis of atrial fibrosis and development of an arrhythmogenic substrate. Circ J. 2013; 77(5): 1171-1179, doi: 10.1253/circj.cj-12-1155, indexed in Pubmed: 23370453.

32. Fuster V, Rydén LE, Cannom DS, et al. American College of Cardiology/American Heart Association Task Force on Practice Guidelines, European Society of Cardiology Committee for Practice Guidelines, European Heart Rhythm Association, Heart Rhythm Society. ACC/AHA/ESC 2006 Guidelines for the Management of Patients with Atrial Fibrillation: a report of the American College of Cardiology/American Heart Association Task Force on Practice Guidelines and the European Society of Cardiology Committee for Practice Guidelines (Writing Committee to Revise the 2001 Guidelines for the Management of Patients With Atrial Fibrillation): developed in collaboration with the European Heart Rhythm Association and the Heart Rhythm Society. Circulation. 2006; 114(7): e257-e354, doi: 10.1161/CIRCULATIONAHA.106.177292, indexed in Pubmed: 16908781.

33. Nichols GA, Reinier K, Chugh SS. Independent contribution of diabetes to increased prevalence and incidence of atrial fibrillation. Diabetes Care. 2009; 32(10): 1851-1856, doi: 10.2337/dc09-0939, indexed in Pubmed: 19794003. 